\title{
Comparative Evaluation of Traditional Susceptibility Testing for MRSA with the PCR Approach
}

\author{
Tim Sandle1, Ilya Azizov², Dmitriy Babenko², Alena Lavrinenko², Antonella Chesca ${ }^{3}$ \\ ${ }^{1}$ Bio Products Laboratory, Elstree, UK \\ ${ }^{2}$ Science Research Center, Karaganda State Medical University, Karaganda, Kazakhstan \\ ${ }^{3}$ Faculty of Medicine, Transilvania University of Braşov, Braşov, Romania \\ Email: timsandle@btinternet.com, ilyazizov@yandex.kz, dbabenko@kgmu.kz, lavrinenko@kgmu.kz, \\ dr.chesca@gmail.com
}

Received 20 October 2014; revised 26 November 2014; accepted 10 December 2014

Copyright (C) 2014 by authors and Scientific Research Publishing Inc.

This work is licensed under the Creative Commons Attribution International License (CC BY). http://creativecommons.org/licenses/by/4.0/

cc) (i) 0 pen Access

\begin{abstract}
Methicillin-resistant Staphylococcus aureus (MRSA) is a multi-drug resistant pathogen, which is responsible for increasing cases of serious diseases, including life-threatening diseases and nosocomial and community-acquired infections. Laboratory identification of MRSA is crucial and essential both for initiation of appropriate antimicrobial therapies and for effective infection control strategies that are designed to limit the spread of MRSA. In spite of the availability of commercial kits for MRSA detection in the market, the Clinical and Laboratory Standards Institute (CLSI) recommends the use of phenotypic methods, such as the disk diffusion method with oxacillin or with cefoxitin, as well as a serial dilution method with oxacillin. Nevertheless, some studies have shown that results obtained with such phenotypic methods are controversial. The aim of the study described in this paper was to comparatively evaluate the traditional susceptibility testing for MRSA with PCR as the gold standard assay. Analysis of collection $(n=68)$ isolates of Staphylococcus aureus revealed that the serial dilution method with oxacillin possessed the highest sensitivity (at $100 \%)$. In contrast, the disk diffusion methods with oxacillin and cefoxitin showed lower sensitivity $(95.83 \%, 95 \%$ CI $(78.81 \%-99.30 \%))$. Furthermore, the borderline value of zone inhibition diameters for cefoxitin might be considered as a risk, and they may give false-susceptible result.
\end{abstract}

\section{Keywords}

MRSA, mecA, Phenotypic Methods, PCR 


\section{Introduction}

Methicillin-resistant Staphylococcus aureus (MRSA) (sometimes referred to as oxacillin-resistant Staphylococcus aureus) is one of the most important healthcare-associated pathogens, and it has gained global attention in recent years [1]. The major threat of MRSA to human health is associated with infectivity, possession of virulence factors and antimicrobial resistance [2] [3]. This is particularly with nosocomial and community-acquired infections, where the young, elderly and the immunocompromised are most at risk. In relation, it has been shown by Honda $\mathrm{H}$ et al. that patients who are colonized with MRSA have a greater risk for developing infection than with methicillin-susceptible Staphylococcus aureus (MSSA) in the intensive care unit [4]. The bacterium primarily commonly colonizes the anterior nares. Other potential sites for infection include the remainder of the respiratory tract, open wounds, intravenous catheters, and the urinary tract.

Methicillin resistance in Staphylococcus aureus is primary provided by the over production of the penicillinbinding protein 2a (PBP2a), which differs from other penicillin-binding proteins as its active site does not bind methicillin or other $\beta$-lactam antibiotics. 2a (PBP2a) is encoded in the mecA gene. This mechanism enables Staphylococcus aureus to survive in presence of penicillin-like antibiotics [5].

Patient screening upon hospital admission with nasal cultures is of great importance for controlling the risk presented by the bacterium. To define Staphylococcus aureus as MRSA in laboratory, either the mecA gene should be detected or a minimum inhibitory concentration (MIC) of oxacillin must be equal or higher than 4 $\mathrm{mg} / \mathrm{ml}$. However, some recent studies showed that some strains of Staphylococcus aureus, carrying the mecA gene have also demonstrated susceptibility to oxacillin [6] [7].

The molecular approach for defining of Staphylococcus aureus as MRSA by detection mecA gene with PCR is not yet available in every bacteriological laboratory; hence the phenotypic tests remain the methods of choice (and are the recommended diagnostic tests by the Clinical and Laboratory Standards Institute (CLSI)). However, the results obtained with phenotypic methods remain controversial (for example, incubation temperature is known to affect the test results). The traditional phenotypic screening method for methicillin resistance is oxacillin disk diffusion test (DDT); to add to the array of phenotypic methods Velasco et al. recently demonstrated that DDT with cefoxitin was more accurate for the detection methicillin resistance [8]. This is because Cefoxitin results are easier to interpret and are thus more sensitive for the detection of mecA-mediated resistance than oxacillin results.

The aim of our study was to evaluate the accuracy of the disk diffusion tests with oxacillin and with cefoxitin (with the PCR method serving as the gold standard for detection MRSA).

\section{Material and Methods}

\subsection{Sample Collection and Bacterial Isolation}

The collection of 68 stains of Staphylococcus aureus with methicillin resistance were obtained from patients with skin and soft tissue infections in Karaganda, Astana, Zhezkazgan and Semey cities from 2012 to 2014. Each of these strains of Staphylococcus aureus were obtained from different hospital departments, including intensive care unit, surgery, trauma unit, obstetrics and gynecology, and others.

Species identification of microorganisms was performed using Matrix-assisted laser desorption/ionizationTime-of-flight (MALDI-TOF) (Microflex, Bruker) with a score of $>1.9$ (Biotyper, Bruker). This method uses a type of mass spectrometry to measure a unique molecular (protein) fingerprint of a microorganism.

\subsection{Phenotypic Identification of MRSA}

All Staphylococcus aureus strains were tested for methicillin resistance using the oxacillin and cefoxitin disk diffusion methods (DDM) according to the Clinical and Laboratory Standards Institute (CLSI). Plates with $\mathrm{MHA}+2 \% \mathrm{NaCl}$ and commercial disks (Bio-Rad) with oxacillin were incubated at $35^{\circ} \mathrm{C}$ for $24 \mathrm{~h}$. and with cefoxitin (Bio-Rad) at $37^{\circ} \mathrm{C}$ for $18-24 \mathrm{~h}$ to allow the microorganisms to grow. Following this, zone inhibition diameters were measured. The results with zone inhibition diameter for oxacillin $(1 \mu \mathrm{g}$ per disc $) \leq 10 \mathrm{~mm}$ and for cefoxitin (30 $\mu \mathrm{g}$ per disc) $\leq 21 \mathrm{~mm}$ indicated resistance to methicillin [9] [10].

The method of serial dilution used Mueller-Hinton broth (MHB) with oxacillin to detect MRSA. In the 96 well plates (Nunc) with broth, samples were inoculated with $10 \mu \mathrm{l}$ of $0.5 \mathrm{McF}$ arland suspensions of the bacterial strains and then incubated at $35^{\circ} \mathrm{C}$ for $24 \mathrm{~h}$. This procedure was performed using an automatic station, Evo 150 
(Tecan). The criterion to define MRSA was $\geq 4 \mu \mathrm{g} / \mathrm{ml}$, as described in CLSI [9].

\subsection{Genotypic Identification of MRSA}

Isolates were grown on Mueller-Hinton at $35^{\circ} \mathrm{C}$ for 18 to $24 \mathrm{~h}$. A single colony of Staphylococcus aureus was used for extraction of DNA using DNAzol Reagent (Invitrogen, USA), according to the manufacture's instruction. The genomic DNA was used as template for detection of mecA gene by PCR.

The primers used to amplify the mecA gene were: GMECAR-1 5'-ACTGCTATCCACCCTCAAAC-3' and GMECAR-2 5'-CTGGTGAAGTTGTAATCTGG-3' (163 bp) as described [11]. Each PCR mixture was $12.5 \mu \mathrm{l}$ SYBR Select Master Mix (Applied Biosystems, USA) (2.0×), $0.5 \mu \mathrm{l}$ of each primer (10 mM), $9.5 \mu \mathrm{l}$ sterile distilled $\mathrm{H}_{2} \mathrm{O}$ and $2 \mathrm{ml}$ DNA template. The PCR program included an initial step at $94^{\circ} \mathrm{C}$ for 5 min followed by 35 cycles of $92^{\circ} \mathrm{C}$ for $2 \mathrm{~min}, 57^{\circ} \mathrm{C}$ for $2 \mathrm{~min}$, and $72^{\circ} \mathrm{C}$ for $1 \mathrm{~min}$, and ended with a final extension step at $72^{\circ} \mathrm{C}$ for 7 min. The Staphylococcus aureus strains ATCC 43300 and ATCC 25923 (American Type Culture Collection, USA) were included as positive and negative controls for mecA gene, respectively. The products of PCR amplification were detected with $2 \%$ agarose gel.

\subsection{Quality Control}

Quality control of discs with antibiotics was performed with using S. aureus ATCC 25923 in accordance with recommendation CLSI. The presence of methicillin resistance was controlled with standard strains: $S$. aureus ATCC 25923 as negative control and S. aureus ATCC 43300 as positive control (Figure 1).

\subsection{Diagnostic Test Evaluation}

The PCR results with detection mecA gene (gold standard) were considered as true values. Calculations of sensitivity, specificity and positive/negative predictive values of phenotypic methods in comparison with genetic assay were calculated using MedCalc for Windows, version 10.2 (MedCalc Software, Ostend, Belgium) [12].

\section{Results}

The collection of clinical Staphylococcus aureus $(n=68)$ were obtained from different hospital departments of Karaganda, Astana, Zheskasgan and Semey (Kazakhstan), including intensive care unit, surgery, neurosurgery, trauma unit, obstetrics and gynecology, pediatry, general and others. The summarized data relating to the isolates is presented in Table 1.

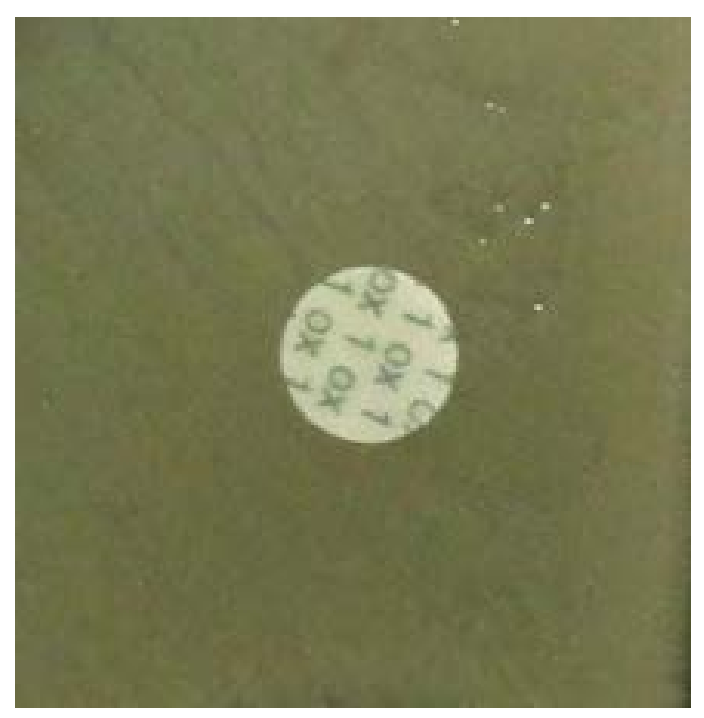

S. aureus ATCC43300 MRSA

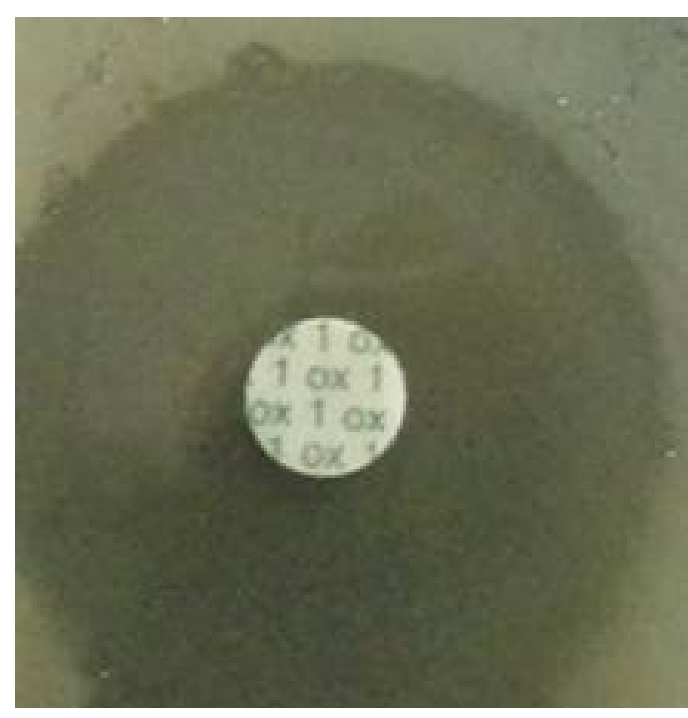

S. aureus ATCC25923 non-MRSA

Figure 1. Phenotypic identification of MRSA. 
Table 1. List of nosocomial strains of Staphylococcus aureus isolated in hospitals of Astana, Karaganda, Semey and Zheskasgan (Republic of Kazakhstan, 2012-2014).

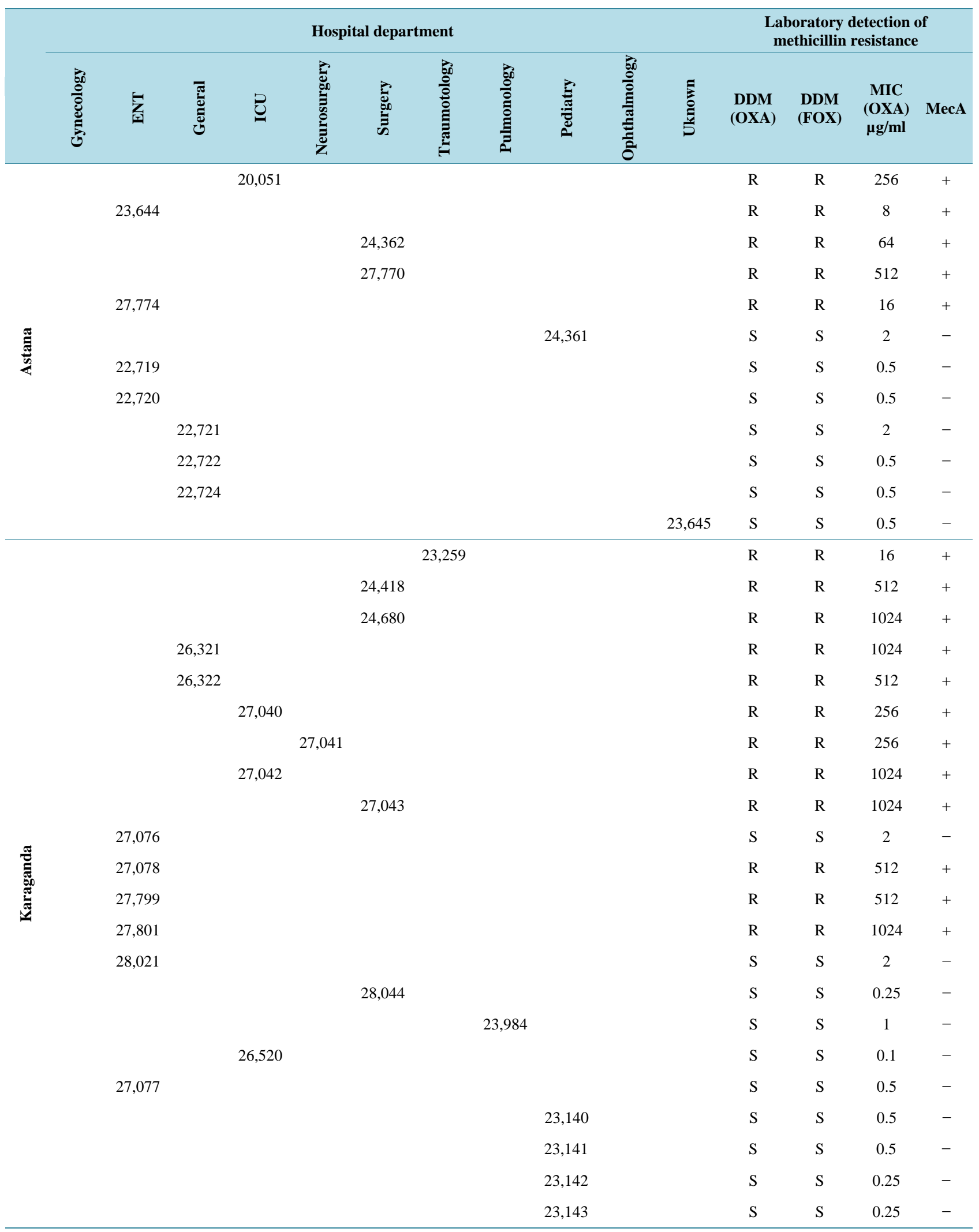




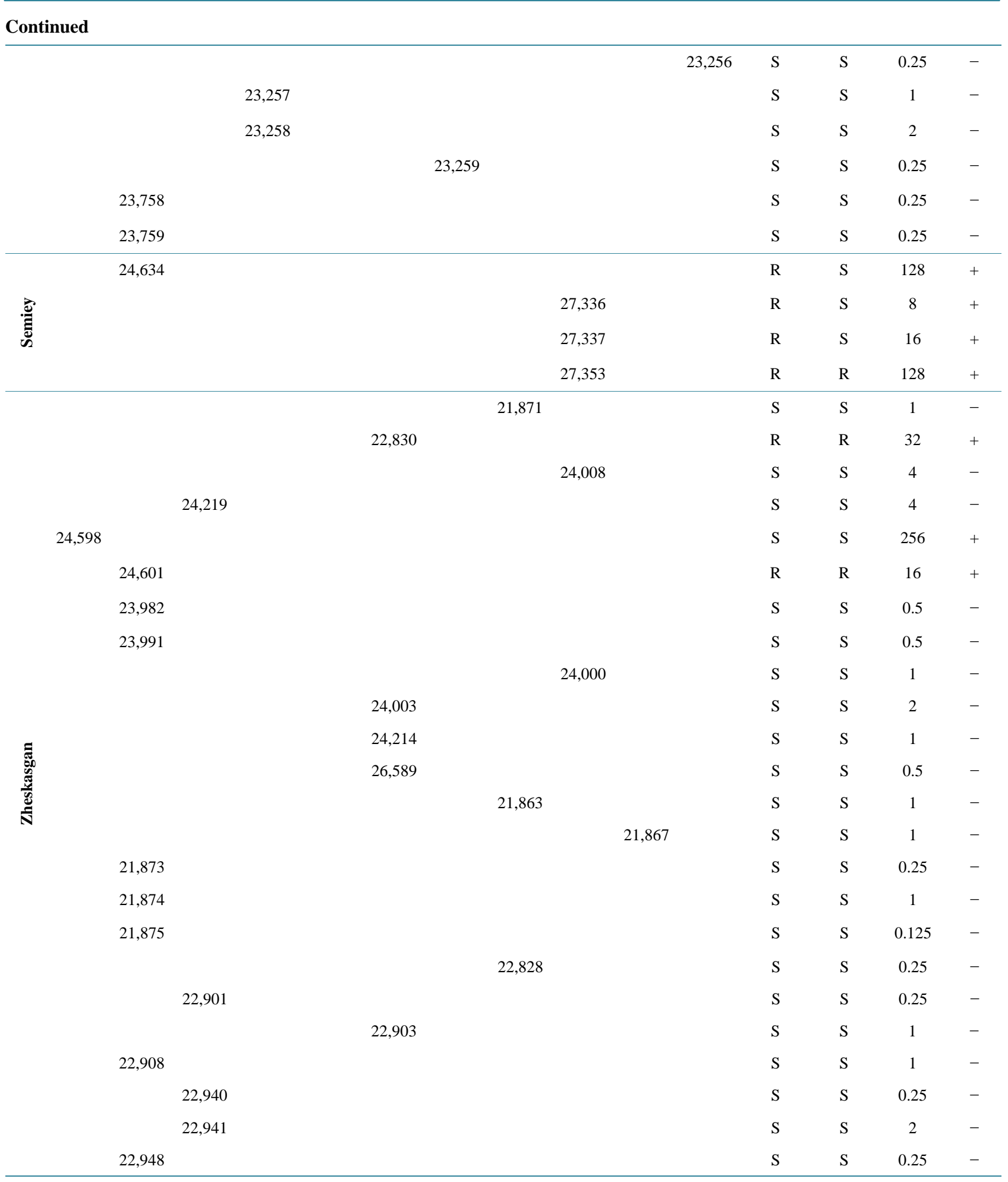

The 68 clinical isolates of Staphylococcus aureus were tested for methicillin resistance with PCR by amplifying mecA gene. 24 of 68 were positive isolates based on predicted 167 bp PCR product (refer to Figure 2).

The comparison of phenotypic detection methods, for defining MRSA (DDM with oxacillin and with cefoxitin and method of serial dilution with oxacillin), with the PCR method (detection of mecA gene), acting as "the gold standard", is summarized in Table 2. 


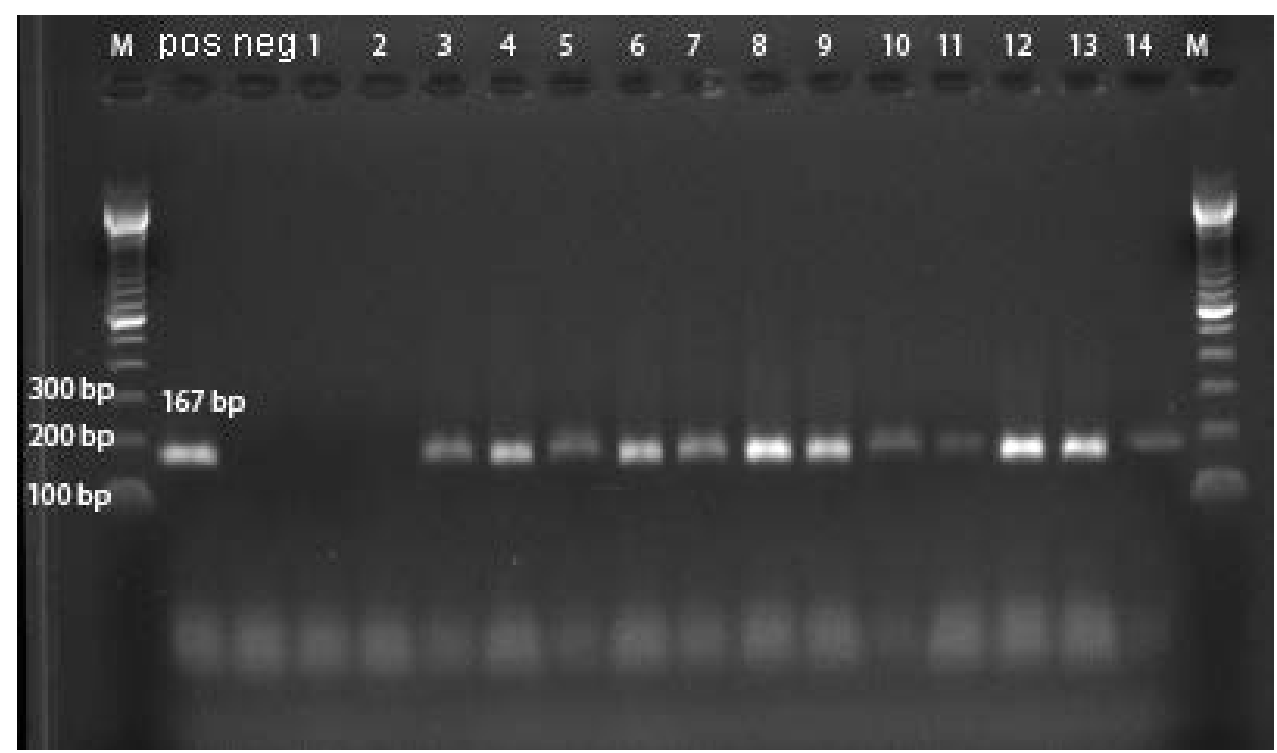

Figure 2. Detection the amplified PCR product of mecA gene ( $2 \%$ agarose gel). M-molecular markers, pos-positive control ( $S$. aureus ATCC43300 strain), neg-negative control (S. aureus ATCC 25923 strain), 1 - 14_clinical isolates of Staphylococcus aureus.

Table 2. The comparison evaluation of the different phenotypic methods compared with PCR.

\begin{tabular}{|c|c|c|c|c|c|c|}
\hline $\begin{array}{l}\text { Phenotypic } \\
\text { method }\end{array}$ & Positive $^{*}$ & Negative & $\begin{array}{c}\text { Sinsitivity (\%) } \\
(95 \% \text { CI) }\end{array}$ & $\begin{array}{l}\text { Specificity (\%) } \\
\text { (95\% CI) }\end{array}$ & $\begin{array}{l}\text { PPV (\%) } \\
\text { (95\% CI) }\end{array}$ & $\begin{array}{l}\text { NPV (\%) } \\
\text { (95\% CI) }\end{array}$ \\
\hline \multicolumn{7}{|c|}{ DDT with oxacillin } \\
\hline Positive & 23 & 0 & $95.83 \%$ & $100 \%$ & $100 \%$ & $97.78 \%$ \\
\hline Negative & 1 & 6 & $(78.81 \%-99.30 \%)$ & $(91.88 \%-100 \%)$ & $(85.05 \%-100 \%)$ & $(88.19 \%-99.63 \%)$ \\
\hline \multicolumn{7}{|c|}{ DDT with cefoxitine } \\
\hline Positive & 20 & 0 & $83.33 \%$ & $100 \%$ & $100 \%$ & $91.67 \%$ \\
\hline Negative & 4 & 6 & $(62.6 \%-95.16 \%)$ & $(91.88 \%-100 \%)$ & (83.01-100\%) & $(80 \%-97.63 \%)$ \\
\hline \multicolumn{7}{|c|}{ Method of serial dilution with oxacillin } \\
\hline Positive & 24 & 2 & $100 \%$ & $95.45 \%$ & $92.31 \%$ & $100 \%$ \\
\hline Negative & 0 & 4 & $(85.62 \%-100 \%)$ & $(84.5 \%-99.31 \%)$ & $(74.83 \%-98.83 \%)$ & $(91.51 \%-100 \%)$ \\
\hline
\end{tabular}

*The presence of mecA gene in isolates of Staphylococcu aureus was considered to be a true positive result. PPV—positive predictive value, NPV - negative predictive value.

\section{Discussion}

Methicillin-resistant Staphylococcus aureus is considered to be a nosocomial pathogen with a wide range of clinical manifestations, including life-threatening diseases such as necrotizing pneumonia and endocarditis [13]. It has been shown that patients colonized with MRSA have an increased risk for developing infection compared with non-colonized patients [2] [14]. Therefore, rapid and accurate identification of multi-drug resistant Staphylococcus aureus is crucial and essential both for initiation of appropriate antimicrobial therapies and for effective infection control strategies to limit the spread of MRSA [15]. In spite of the fact that there are many new rapid and less costly methodologies, the traditional susceptibility testing, such as disk diffusion method with oxacillin or cefoxitin, is available in every bacteriological laboratory and these methods can be performed easily to detect MRSA. It also remains that such methods are the recommended ones of the CLSI.

\section{Conclusions}

Our study showed sufficiently high enough diagnostic characteristics from the traditional techniques for detec- 
tion methicillin resistance of Staphylococcus aureus: such as the serial dilution method (100\% sensitivity) and disk diffusion tests with oxacillin (95.83\% sensitivity). These results are in accordance with previously reported studies [16] [17]. Although some publications revealed the higher sensitivity for disk diffusion test with cefoxitin (95\% - 100\%), in our research the sensitivity for DDT with cefoxitin was considerably lower (83.33\% (95\% CI 62.6\% - 95.16\%)). Interestingly, all discrepant PCR and disk diffusion test results with cefoxitin were associated with border zone inhibition diameters to breakpoint parameters for being susceptible ( $\geq 22 \mathrm{~mm}$ ). Repeated tests on these discrepant results showed the "resistant" results were instead "susceptible" and this increased sensitivity of disk diffusion test with cefoxitin up to $95.83 \%$. Thus, results with borderline zone inhibition can be considered as false-negative results. Having chance to compare phenotypic screening results with PCR allow double-checking the discrepant results, otherwise false-susceptible results can be considered as a true results. These results exemplify the concerns with biased and imprecise breakpoints in relation to the classical methods.

At the same time, examples of Staphylococcus aureus with borderline oxacillin resistance being mecA-negative have been reported to be resistant due to other mechanisms, such as the hyperproduction of $\beta$-lactamase [18]. In addition, isolates of Staphylococcus aureus having mecA gene have been reported to be phenotypically susceptible to oxacillin [7] [19] Whilst the PCR approach stands as an ultimate method for detecting resistance to methicillin where such technology cannot be incorporated, our results demonstrated that the combination of two or more pheonotypic tests will provide more confidence in the result obtained [20].

\section{References}

[1] Yi, J.Y. and Kim, E.C. (2010) Microbiological Characteristics of Methicillin-Resistant Staphylococcus aureus. Korean Journal of Clinical Microbiology, 13, 1-6. http://dx.doi.org/10.5145/KJCM.2010.13.1.1

[2] Cosgrove, S.E., et al. (2003) Comparison of Mortality Associated with Methicillin-Resistant and Methicillin-Susceptible Staphylococcus aureus Bacteremia: A Meta-Analysis. Clinical Infectious Diseases, 36, 53-59. http://dx.doi.org/10.1086/345476

[3] Chambers, H.F. (2005) Community-Associated MRSA—Resistance and Virulence Converge. The New England Journal of Medicine, 352, 1485-1487. http://dx.doi.org/10.1056/NEJMe058023

[4] Honda, H., Krauss, M.J., Coopersmith, C.M., Kollef, M.H., Richmond, A.M., Fraser, V.J. and Warren, D.K. (2010) Staphylococcus aureus Nasal Colonization and Subsequent Infection in Intensive Care Unit Patients: Does Methicillin Resistance Matter? Infection Control and Hospital Epidemiology, 31, 584-591. http://dx.doi.org/10.1086/652530

[5] Hiramatsu, K., Cui, L.Z., Kuroda, M. and Ito, T. (2001) The Emergence and Evolution of Methicillin-Resistant Staphylococcus aureus. Trends in Microbiology, 9, 486-493. http://dx.doi.org/10.1016/S0966-842X(01)02175-8

[6] Labrou, M., Michaila, G., Ntokoua, E., Pittarasb, T.E., Pournarasa, S. and Tsakris, A. (2012) Activity of Oxacillin versus That of Vancomycin against Oxacillin-Susceptible mecA-Positive Staphylococcus aureus Clinical Isolates Evaluated by Population Analyses, Time-Kill Assays, and a Murine Thigh Infection Model. Antimicrobial Agents and Chemotherapy, 56, 3388-3391. http://dx.doi.org/10.1128/AAC.00103-12

[7] Saeed, K., Dryden, M. and Parnaby, R. (2010) Oxacillin-Susceptible MRSA, the Emerging MRSA Clone in the UK? Journal of Hospital Infection, 76, 267-268. http://dx.doi.org/10.1016/j.jhin.2010.03.004

[8] Velasco, D., Tomas, M., Cartelle, M., Beceiro, A., Perez, A., Molina, F., Moure, R., Villanueva, R. and Bou, G. (2005) Evaluation of Different Methods for Detecting Methicillin (Oxacillin) Resistance in Staphylococcus aureus. Journal of Antimicrobial Chemotherapy, 55, 379-382. http://dx.doi.org/10.1093/jac/dki017

[9] CLSI (2013) Performance Standards for Antimicrobial Susceptibility Testing; CLSI Approved Standard M100-S23. Clinical and Laboratory Standards Institute, Wayne.

[10] CLSI (2009) Performance Standards for Antimicrobial Susceptibility Testing M100-S19; Nineteenth Informational Supplement. Vol. 29, Clinical and Laboratory Standards Institute, Wayne.

[11] Mehrotra, M., Wang, G. and Johnson, W.M. (2000) Multiplex PCR for Detection of Genes for Staphylococcus aureus Enterotoxins, Exfoliative Toxins, Toxic Shock Syndrome Toxin 1, and Methicillin Resistance. Journal of Clinical Microbiology, 38, 1032-10235.

[12] Parshall, M. (2013) Unpacking the $2 \times 2$ Table. Heart \& Lung, 42, 221-226. http://dx.doi.org/10.1016/j.hrtlng.2013.01.006

[13] Deleo, F.R., Otto, M., Kreiswirth, B.N. and Chambers, H.F. (2010) Community-Associated Meticillin-Resistant Staphylococcus aureus. Lancet, 375, 1557-1568. http://dx.doi.org/10.1016/S0140-6736(09)61999-1

[14] Kalra, L., Camacho, F., Whitener, C.J., Du, P., Miller, M., Zalonis, C. and Julian, K.G. (2013) Risk of Methicillin-Resistant Staphylococcus aureus Surgical Site Infection in Patients with Nasal MRSA Colonization. American Journal of 
Infection Control, 41, 1253-1257. http://dx.doi.org/10.1016/j.ajic.2013.05.021

[15] Cox, R.A., Conquest, C., Mallaghan, C. and Marples, R.R. (1995) A Major Outbreak of Methicillin-Resistant Staphylococcus aureus Caused by a New Phage-Type (EMRSA-16). Journal of Hospital Infection, 29, 87-106. http://dx.doi.org/10.1016/0195-6701(95)90191-4

[16] Boutiba-Ben Boubaker, I., Ben Abbes, R., Ben Abdallah, H., Mamlouk, K., Mahjoubi, F., Kammoun, A., Hammami, A. and Ben Redjeb, S. (2004) Evaluation of a Cefoxitin Disk Diffusion Test for the Routine Detection of Methicillin- Resistant Staphylococcus aureus. Clinical Microbiology and Infection, 10, 762-765. http://dx.doi.org/10.1111/j.1469-0691.2004.00919.x

[17] Salimnia, H. and Brown, W.J. (2005) Detection of Oxacillin Resistance in Staphylococcus aureus: Comparison of Phoenix Oxacillin and Cefoxitin MICs, MicroScan Oxacillin MIC, Oxacillin and Cefoxitin Disk Diffusion, and mecA Gene Detection. The Interscience Conference on Antimicrobial Agents and Chemotherapy (ICAAC), Washington DC, 16-19 December 2005.

[18] Brown, D.F., Edwards, D.I., Hawkey, P.M., Morrison, D., Ridgway, G.L., Towner, K.J., et al. (2005) Guidelines for the Laboratory Diagnosis and Susceptibility Testing of Methicillin-Resistant Staphylococcus aureus (MRSA). Journal of Antimicrobial Chemotherapy, 56, 1000-1018. http://dx.doi.org/10.1093/jac/dki372

[19] Sakoulas, G., Gold, H.S., Venkataraman, L., DeGirolami, P.C., Eliopoulos, G.M. and Qian, Q.F. (2001) MethicillinResistant Staphylococcus aureus: Comparison of Susceptibility Testing Methods and Analysis of mecA-Positive Susceptible Strains. Journal of Clinical Microbiology, 39, 3946-3951. http://dx.doi.org/10.1128/JCM.39.11.3946-3951.2001

[20] Sandle, T., Babenko, D., Lavrinenko, A., Azizov, I. and Chesca, A. (2014) The Current State of PCR Approach in Detection and Identification of Carbapanem Hydrolysis $\beta$-Lactamases Genes. European Journal of Parenteral \& Pharmaceutical Sciences, 19, 153-164. 
Scientific Research Publishing (SCIRP) is one of the largest Open Access journal publishers. It is currently publishing more than 200 open access, online, peer-reviewed journals covering a wide range of academic disciplines. SCIRP serves the worldwide academic communities and contributes to the progress and application of science with its publication.

Other selected journals from SCIRP are listed as below. Submit your manuscript to us via either submit@scirp.org or Online Submission Portal.
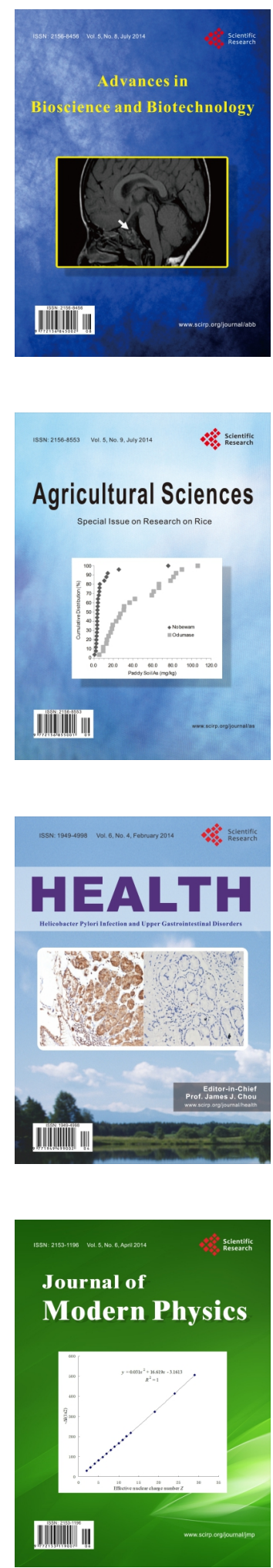
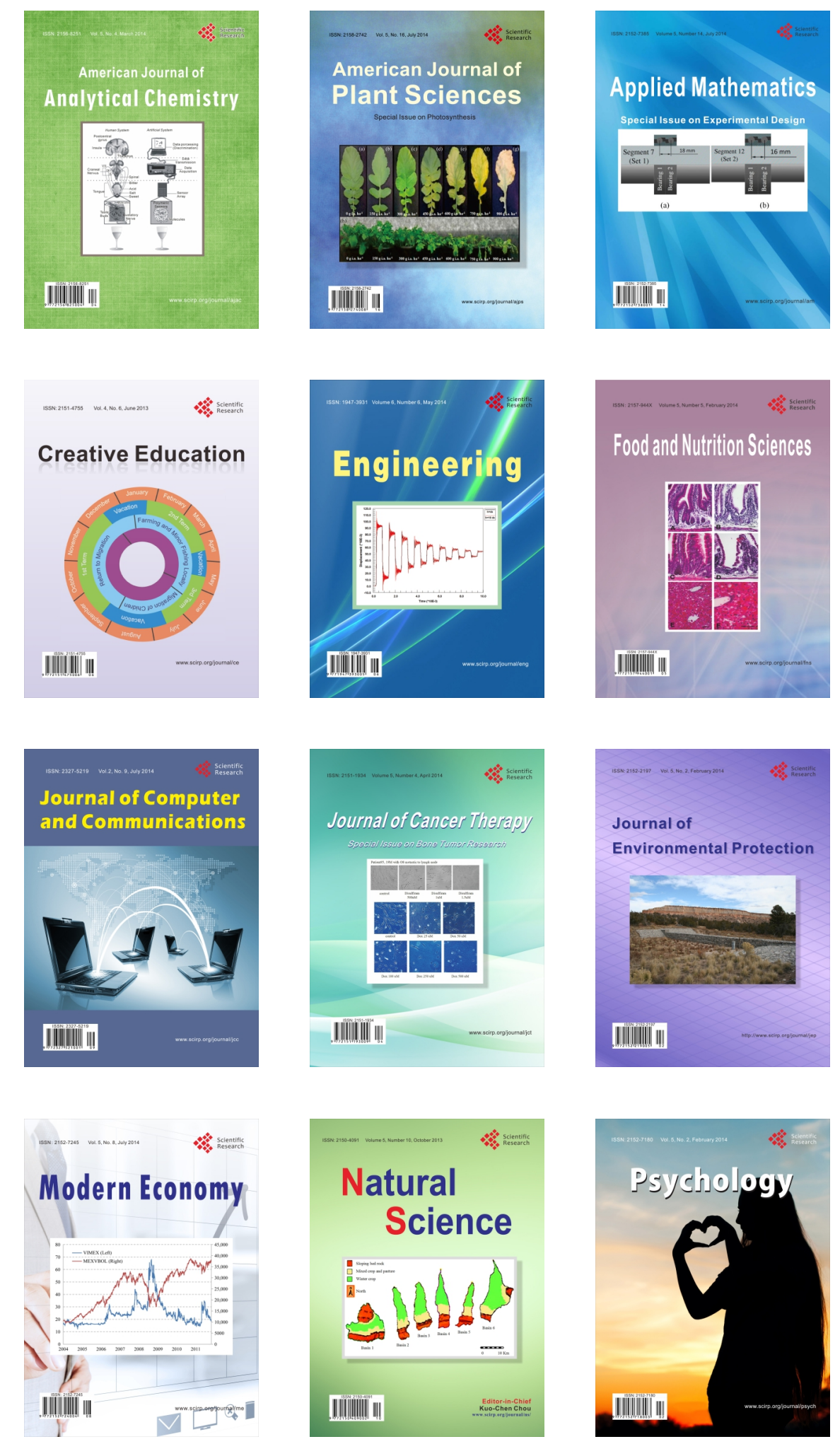